Original Research Paper

\title{
Analyze the Absorption Properties and I-V Characterization of Dye Sensitized Solar Cell Using Ruthenium Dye
}

\author{
Anees Ur Rehman, Farooq Aslam and Haseeb Ahmad Khan \\ Department of Electrical Engineering, Sarhad University of Sciences and Information Technology, Peshawar Pakistan
}

Article history

Received: 25-10-2014

Revised: 24-11-2014

Accepted: 18-12-2014

Corresponding Author: Anees Ur Rehman,

Department of Electrical Engineering, Sarhad University of Sciences and Information Technology, Peshawar, Pakistan Email: anees.ee@suit.edu.pk

\begin{abstract}
In this study, Dye Sensitized Solar Cells (DSSC) has been fabricated using natural organic dye extracted from Ruthenium Dye and its I-V characterization and absorption properties have been analyzed. It is observed that the selected natural dye absorbed all visible light and supports electrons motion across the semiconductor interface. The dye acts as sensitizer because the titanium dioxide $\left(\mathrm{TiO}_{2}\right)$ cannot absorb the visible light itself as it absorbs higher energy ultraviolet light. Carbon coated electrode was used as counter electrode for electrons collection. Photovoltaic parameters like short circuit current density (Jsc), open circuit Voltage (Voc), Fill Factor (FF) and overall efficiency for fabricated cell were $11.52 \mathrm{~mA} / \mathrm{cm}^{2}, 0.70 \mathrm{~V}, 0.61$ and $4.47 \%$ under $110 \mathrm{~mW} / \mathrm{cm}^{2}$ illuminations respectively. Idea of such cells facilitates to reduce the fabrication cost with fine efficiency.
\end{abstract}

Keywords: Solar Cell, Ruthenium Dye, Titanium Dioxide, Indium Tin Oxide

\section{Introduction}

Photovoltaic cells are the best source. A solar cell consists of a semiconductor material with a certain band gap "EG" and thickness. Electrons of the valence band absorb the photon's energy falling on semiconductor and thus promoted to conduction band. Unfortunately, not all of the incident photons contribute to photo-generation. These losses are called non-absorption losses. In addition to the efficiency improvement for the SiGe-based solar cell, the temperature sensitivity is another important parameter for the real application (Liao and Chen, 2011). The recently discovered thin film cells based on mesoscopic organic and inorganic semiconductors are attractive alternatives due to their three-dimensional structure which offer the prospect of low cost fabrication. The prototype of these family devices is the Dye-Sensitized Solar Cell (DSSC), which accomplishes the photoelectric efficiency over a wide span of visible light spectrum with the association of a sensitizer as light absorbing material having a wide band gap semiconductor of mesoporous morphology. DSSC can work effectively in low light conditions and have high quantum efficiency as compare to that of amorphous silicon solar cells. Recent research has indicated that the photoelectric conversion efficiency of DSSC can exceed previous solar cells by 10-11\% (Grätzel, 2009).
Moreover, the probability of interactions between photons and dye in the module can be increased and more electrons can be injected into the $\mathrm{TiO}_{2}$ semiconductor to increase the photoelectric conversion efficiency of DSSC (Grätzel, 2009; Choi et al., 2010). The DSSC consists of a dye covered, nanocrystalline $\mathrm{TiO}_{2}$ (titanium dioxide) layer and an electrolyte containing a redox mediator $\left(\mathrm{I}^{-} / \mathrm{I}_{3}{ }^{-}\right)$encapsulated between two glass plates (Bazargan et al., 2011). A monolayer of dye molecules is adsorbed on the surface of the $\mathrm{TiO}_{2}$ nanoparticles; the electrolyte fills the pores of nanocrystalline $\mathrm{TiO}_{2}$ film. The wide nanoporous surface allows the adsorption of a sufficient number of dye molecules for efficient light harvesting. Upper and lower plates are coated with a transparent conducting oxide. Indium Tin Oxide (ITO) is most commonly used. The ITO glass at the counter electrode is coated with few layers of carbon, so that the redox reaction may be catalyzed with the electrolyte. Due to its crucial role in such systems, considerable efforts have been directed towards the development and improvement of new families of organic dyes (Yum et al., 2007) and the widely effective so far are transition metal compounds e.g., ruthenium polyridyl complexes. Unfortunately, this type of dye is expensive and emerges as public environmental awareness. Alternatively, natural fruits that are rich in ruthenium dye such as Hylocereus 
costaricensis and Vaccinium corymbosum can be used with best efficiency in DSSC. Since the preparation of synthetic dyes normally requires multistep procedures, organic solvents and, in most cases, time consuming chromatographic purification procedures, there is interest towards the possible use of natural dyes which can be easily extracted from fruits, vegetable and flowers with minimal chemical procedures (Polo et al., 2004). Our aim was to analyze the dye characterization and the photovoltaic performance of DSSC sensitized with natural Ruthenium dye as photo-sensitizer.

\section{Experimental Work}

\section{Materials}

The Ruthenium dye was used as extraction solvent. Transparent conductive indium tin oxide coated glass and Titanium nanoxide powder were used as electrode plates and electron transport layer respectively, carbon black as counter electrode and tri-iodide redox mediator $\left(\mathrm{I}^{-} / \mathrm{I}_{3}{ }^{-}\right)$were used as electrolyte.

\section{Preparation of DSSC}

The anode paste was prepared by adding $0.8 \mathrm{~g}$ of the titanium dioxide nano powder with $3 \mathrm{~g}$ of N-methyl 2Pyrolodin (NMP) solution. Ohm meter was used to test the conductivity of the slide. Before coating the slide with the titanium dioxide paste, the glass slides were cleaned with alcohol. Scotch tape was applied on three pieces of the conductive side of glass slide. The scotch tape pieces masked $1 \mathrm{~cm}$ strip on three sides of both the anode and cathode ITO glass having resistance of 22 $\mathrm{Ohm} / \mathrm{cm}$ each. The $0.5 \mathrm{~cm}$ of the 4 th side was revealed for the connecting the alligator clips for sealing of the manufactured cell. Some drops of titanium dioxide paste were poured in the well of anode slide. The same chemicals were selected for the cathode paste except carbon black was used instead of titanium dioxide. Same doctor blading technique was applied for the carbon cathode. Both of the plates were then placed on hot plate and sintered them at $350^{\circ} \mathrm{C}$ but the timings for anode and cathode were different i.e., the anode was heated until the color is turned to brown and then turned white as its original color. This took about $4 \mathrm{~h}$, while the cathode was placed on hot plate for about $1 \mathrm{~h}$. The paste was distributed uniformly by doctor blading technique. The working electrode $\left(\mathrm{TiO}_{2}\right.$ electrode) was immersed in fresh Ruthenium dye for $24 \mathrm{~h}$. The dyed anode was placed with face up and the carbon coated cathode was placed on anode with face down so that the conductive sides were facing each other. The $1 \mathrm{~cm}$ of each slides were exposed so these edges became the contact points for positive and negative electrodes and thus the cell was easy for testing with voltmeter. The two binder clips were placed at the slides where they overlapped to hold the slides together. Two drops of the electrolyte solution was added to one edge of the slides. Then the binder clips were alternately opened and closed so the solution was drawn into the cell due to capillary action.

\section{DSSCs Performance}

For excellent interparticle connectivity, there should be no gaps between the coated layers. The I-V characteristic plot is recorded with $15 \mathrm{k} \Omega$ potentiometer as variable load under $110 \mathrm{~mW} / \mathrm{cm}^{2}$ illuminations.

\section{Results}

\section{Characterization of Nanostructure $\mathrm{TiO}_{2}$}

The Scanning Electron Microscope (SEM) image of top view of $\mathrm{TiO}_{2}$ paste coated on ITO electrode is shown in (Fig. 1). The DSSCs nanostructured photonanode were fabricated on ITO glass substrates. The film is about 15-20 $\mu \mathrm{m}$ thick. The SEM image shows that there were no fractures and no gaps in the $\mathrm{TiO}_{2}$ film particles. This indicates best inter particles conductivity.

\section{Spectral Response of Photo Anode in UV and Visible Region}

The dye, which is typically an organic complex, is excited by absorption of photons. The onset of the absorption is in the range of $700 \mathrm{~nm}$ for most of dyes, which corresponds to photon energy of $1.72 \mathrm{eV}$. The potential of the dye redox couple is between -0.7 and -0.8 $\mathrm{V}$. The lifetime of the excited state is in the nanosecond range. In DSSC, the properties of photo sensitizer are one of the largest aspects influencing the solar cell Performance: e.g., the absorption (Fig. 2) shows the light absorption spectrum from organic fruit dye i.e., Ruthenium dye. Property of photo sensitizer decides directly the range of photo response of the solar cell. Wide absorption enlarge into the near-IR region is essential for broad harvesting the solar spectrum, making a large photo current and resulting in efficient solar-cell performance. Thus, the molecular structure of the photo sensitizer must be well designed for use in DSSCs to produce efficient solar-cell performance. The molecular structure of the Ruthenium dye is shown in (Fig. 3).

\section{I-V Characteristics of Fabricated Cell}

DSSCs with natural Ruthenium as dye and carbon as counter electrode is illustrated with the help of I-V characteristics as shown in the (Fig. 4). The values for short circuit current (Jsc), opencircuit voltage; Fill Factor (FF) and overall efficiency $\eta(\%)$ for fabricated cell are summarized in (Table 1). In our experimental work the anode with $\mathrm{TiO}_{2}$ film, consist of $20 \mathrm{~nm}$ nano particles and the effective area of DSSC is $70.92 \mathrm{~cm}^{2}$. 


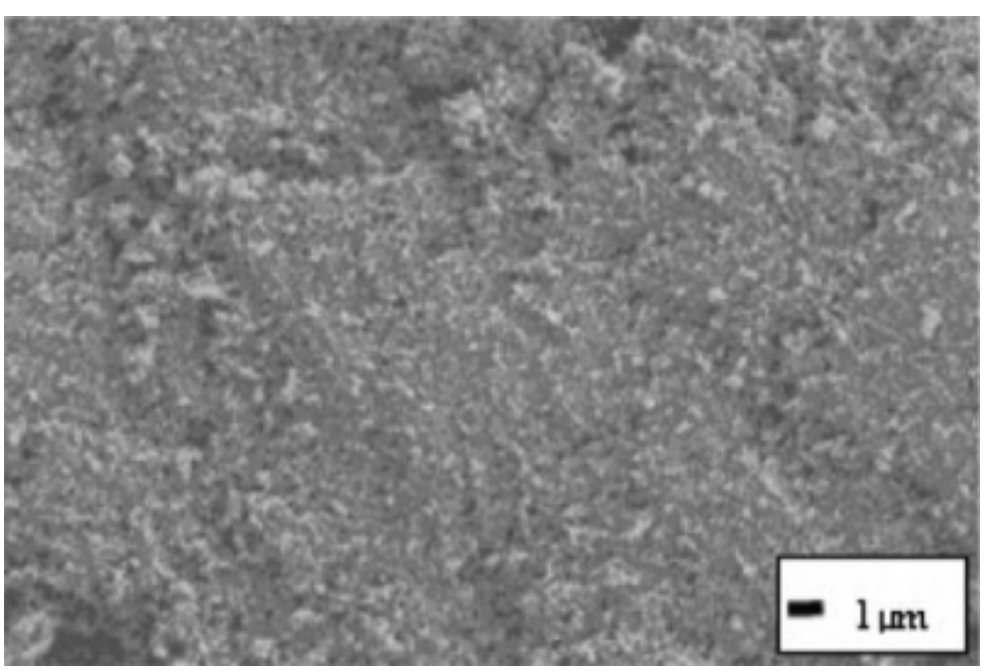

Fig. 1. Top view of SEM image of $\mathrm{TiO}_{2}$ coated film on ITO glass

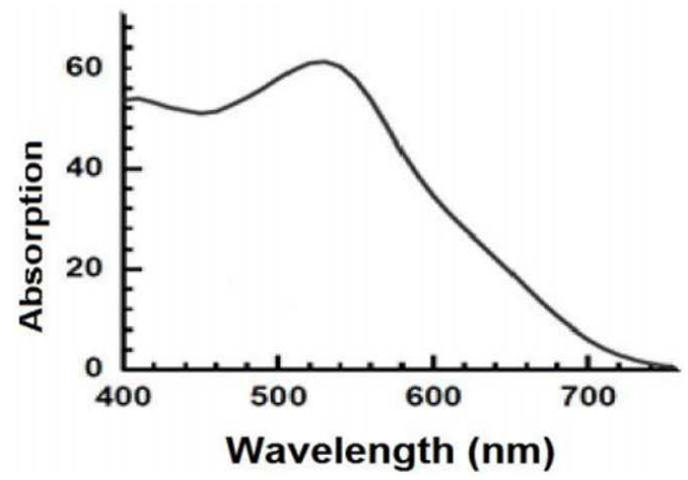

Fig. 2. Spectral response of ruthenium dye

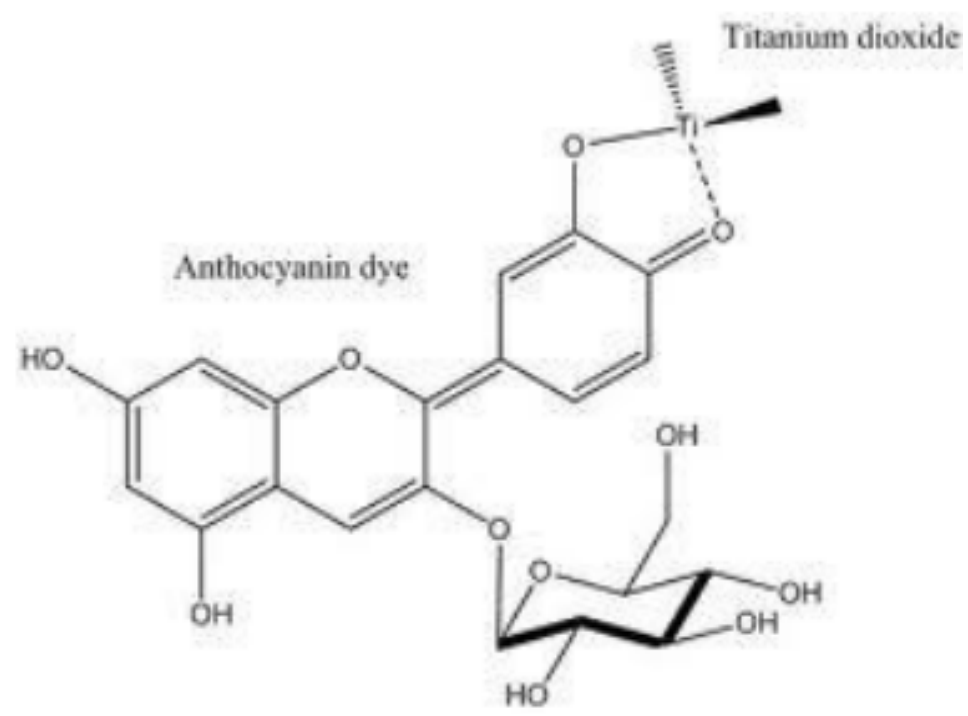

Fig. 3. Molecular structure of ruthenium dye 


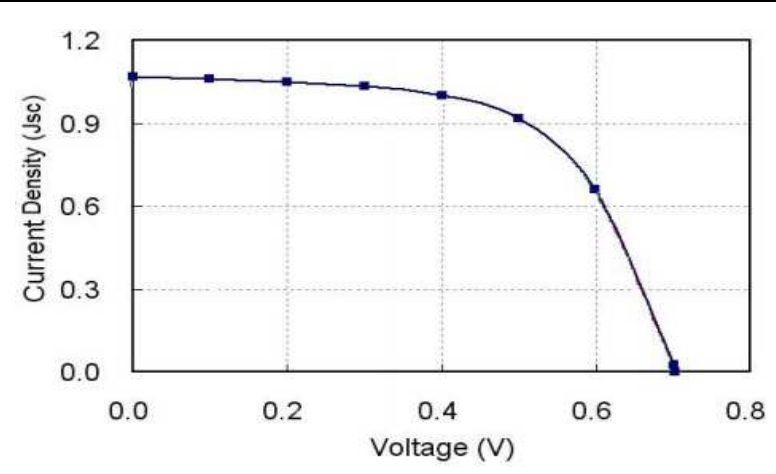

Fig. 4. I-V Characteristics of DSSC

Table 1. Photoelectric parameters of DSSC

\begin{tabular}{llll}
\hline $\mathrm{Jsc}\left(\mathrm{mA} / \mathrm{cm}^{2}\right)$ & $\operatorname{Voc}(\mathrm{V})$ & $\mathrm{FF}$ & $\eta(\%)$ \\
\hline 11.52 & 0.70 & 0.61 & 4.47 \\
\hline
\end{tabular}

\section{Conclusion}

A new type of photovoltaic cell with Ruthenium dye as sensitizer is investigated. The cell was very simple to fabricate. The cell has the potential of a low cost photovoltaic option because of using natural Ruthenium dye as an alternative sensitizer for DSSCs is promising and carbon as counter electrode instead of platinum. The joint struggles by the fabrication with nano-structured thin films have led to maximum photoelectric conversion efficiency under AM 1.5 of $4.47 \%$ for tested DSSC module with an effective area of $70.92 \mathrm{~cm}^{2}$. From our results, it is possible to obtain over $7 \%$ photoelectric conversion efficiency for largescale practical DSSC in the near future if we could get the optimum design and best performance.

\section{Acknowledgement}

We thank Dr. Najeeb Ullah (Director, Energy Center, University of Engineering and Technology (UET) Peshawar, Pakistan) and Engr. Prof. Dr. Azzam Ul Asar (Dean, UET Peshawar, Pakistan) for all the advices and explanations essential for the conduct of this article.

\section{Funding Information}

The research was a joint venture program between Cambridge University, UK and University of Engineering and Technology (UET) Peshawar, Pakistan. All the funding for the research was provided by the UET Peshawar.

\section{Author's Contributions}

Authors equally contributed to this article.

\section{Ethics}

The research publication meets all the Ethical Standard.

\section{References}

Bazargan, M.H., M. Malekshahi Byranvand, A. Nematikharat and L. Fatholahi, 2011. Natural pomegranate juice as photosensitizers for DyeSensitized Solar Cell (DSSC). Iran. Res. Organiz. Sci. Technol., 5: 360-362.

Choi, H., J.J. Kim, K. Song, J. Ko and K. Nazeeruddin et al., 2010. Molecular engineering of panchromatic unsymmetrical squaraines for dye-sensitized solar cell applications. J. Mat. Chem., 20: 3280-3286. DOI: $10.1039 / \mathrm{b} 926863 \mathrm{~d}$

Grätzel, M., 2009. Recent advances in sensitized mesoscopic solar cells. Acc. Chem. Res., 42: 17881798. DOI: $10.1021 /$ ar900141y

Liao, M.H. and C.H. Chen, 2011. The investigation of optimal Si-SiGe hetero-structure thin-film solar cell with theoretical calculation and quantitative analysis. IEEE Trans. Nano Technol., 10: 770-773. DOI: 10.1109/TNANO.2010.2077647

Polo, A.S., M.K. Itokazu and N.Y. Murakami Iha, 2004. Coord. Chem. Rev., 248: 1343-1361. DOI: $10.1016 /$ j.ccr.2004.04.013

Yum, J.H., P. Walter, S. Huber, D. Rentsch and T. Geiger et al., 2007. Efficient far red sensitization of nanocrystalline $\mathrm{TiO}_{2}$ films by an unsymmetrical squaraine dye. J. Am. Chem. Soc., 129: 10320-10321. DOI: 10.1021/ja0731470 